\title{
Project Management Software Use and Influence on Project Success
}

\author{
Silibaziso Nobukhosi Magwali and Stanley Fore
}

\begin{abstract}
The research explored how application of Project Management Software (PMS) influences project success. A case of NPOs in the Western Cape was used. The research objectives were 1) Establish if PMS is applied in the NPO's work. 2) Determine employee's interactions with PMS relative to project success 3) Identify limitations of current PMS being used.

The sample group consisted of 132 project-implementing NPO's in the Western Cape. The research instrument used were questionnaires, which were administered physically and online. The data was analyzed using the Statistical Package for Social Sciences (SPSS).

The research revealed that PMS is utilized in a significant number of organisations with the most popular ones used being MS Project, Project Manager and Jira. Most users utilize PMS on a weekly or monthly basis especially during the project planning and execution stages. The limitations of the software include that it can over-complicate issues, be time-consuming and costly.
\end{abstract}

Keywords-Project, Project Management, Project Management Software, Project Success

\section{INTRODUCTION}

It is the goal of all organisations (business, civil society and government), to effectively plan, manage and deliver high quality outcomes, most often, as prescribed by the end-user [1]. The attainment of the afore-mentioned is often accepted as a good measure of project success. Though project success is often seen as relative, it remains a vital component for growing and successful organisations [2].

It is essential therefore that organisations with project-environments fully engage and support the development and implementation of projects [2]. This enables their success and ultimately feeds into their respective development and growth.

A proven enabler to project success is the employment of stable and repeatable systems and processes [3]. The rise in Information and Communication Technology (ICT) has brought about numerous systems and technologies that aid in the attainment of project success. An example of this being Project Management Software (PMS).

Silibaziso Nobukhosi Magwali and Stanley Fore, Cape Peninsula University of Technology, Faculty of Business, Department of Management and Project Management, Cape Town, South Africa
PMS can be generic or specialised, and are usually designed with project lifecycles in mind to enable the most efficient planning, control and management of projects [4]. The influence of ICT and PMS on projects has received huge interest from fellow researchers and the project management industry over the last years.

However, research on ICT and respective PMS impact in the NPO sector has been less frequent. Moreover, there is less real project data known of the projects of NPOs in South Africa. The researcher therefore elected to study a case of NPOs in the Western Cape.

Most NPOs receive their funding from various sources including corporates, high net-worth individuals, international agencies, amongst others, with whom they have stringent agreements on the use of funds for successful projects [5]. It is because of such conditions that most NPO's are taking strides to employ more project-based approaches when tackling their work.

This paper is significant in that it gives a fresh perspective, utilising real project data of the project scenarios of NPOs in the Western Cape.

\section{A. Purpose of the Study}

Though strides have been taken to ensure the availability and application of technology, there still exists some disparity in the envisaged use compared to the actual use [6]. This disparity is concerning especially in light of the advancement of end-user centric technology. The application of technology such as PMS, could be the answer to unlocking success in projects especially where sometimes a large scope and high degree of complexity can prove to be very challenging [7].

This is sometimes the case with NPOs where there is a growing demand for the improvement of various infrastructure and service delivery in South Africa as a whole [8]. Though this is seen as primarily a burden for government, NPOs also play a pivotal role in the socio-economic development of South Africa and as such, optimum productivity is encouraged. Moreso, in the challenging economic, social and political environment in South Africa, NPOs are on the lookout of how to better to do their work [9].

The purpose of this research was therefore to explore how the application of PMS influences project success. A case of project-implementing NPOs in the Western Cape was used to address the research objectives and questions. 


\section{B. Research sub-objectives and questions}

TABLE I: THEMATIC RESEARCH OBJECTIVES AND QUESTIONS

\begin{tabular}{l|l}
$\begin{array}{l}\text { Research } \\
\text { Objectives }\end{array}$ & \multicolumn{1}{c}{ Research questions } \\
$\begin{array}{l}\text { Establish if PMS is applied in the } \\
\text { NPO's work. }\end{array}$ & $\begin{array}{l}\text { Which project management } \\
\text { software are used within the } \\
\text { NPO's? }\end{array}$ \\
$\begin{array}{l}\text { Determine employee's interactions } \\
\text { with PMS relative to project } \\
\text { success. }\end{array}$ & $\begin{array}{l}\text { What are employee's } \\
\text { perceptions of the PMS in } \\
\text { use? }\end{array}$ \\
\hline $\begin{array}{l}\text { Identify the limitations of current } \\
\text { PMS being used. }\end{array}$ & $\begin{array}{l}\text { What are the shortcomings } \\
\text { the success of the projects? }\end{array}$ \\
\hline
\end{tabular}

The table shows the research objectives in correlation to the research questions that were used to guide the study.

\section{LITERATURE REVIEW}

\section{A. Projects, Project Management and Project Success}

A project is a temporary endeavour to achieve specific objectives in a defined time with the end- product being a unique product/service [10], [11]. Due to the importance and contribution of successful projects to value addition in an organisation, it is pivotal to find ways in which projects can be implemented and managed in organisations [2]. Therefore, at the heart of projects and how they perform is project management.

Project management is a dynamic process that utilizes the appropriate resources of the organisation in a controlled and structured manner to achieve clearly defined objectives identified as strategic needs [10]. Furthermore, it is stated that this is usually accomplished through the integration of the project management processes of initiating, planning, executing, monitoring, controlling and closing. If done well, this often yields project success.

Reference [13] defines project success as how well projects deliver the benefits required by business strategies in order to meet wider business objectives and to create value. Project success is very important for organisations as it has a direct link in the end to the innovation and business success of the very same entity. The most common indicators of project success are amongst others quality, cost, time and stakeholder acceptance [14].

\section{B. Project Management Software}

The importance of effective and repeatable systems and processes that promote the efficiency and effectiveness of projects cannot be understated [15]. One such example is that of reliable PMS that are designed to assist project teams, to meet the needs of customers while being efficient and maintainable.

PMS assists in various functions like project planning, scheduling, resource allocation and change management [4]. Existing examples include Microsoft Project, Trello, Smartsheet and Jira amongst others. Some of the factors usually considered in the due diligence process of selecting PMS are ease of on boarding/ use, scalability and user support [16].

PMS is however not without its limitations; the advantages of the software are not remarkably visible for small projects as compared to the big projects, and they may prove to be disruptive to the workflow especially where there is a lack of local context for project management activities and challenges [17].

\section{Non-Profit Organisations}

NPOs exist as trusts, companies or other association of persons who are established for a public purpose, based on common interest to take action on a particular subject or issue [18].

Some of the main interesting characteristics of NPOs include their dominance of social motives, values and goals over financial ones, a diversity of stakeholders, and an action-oriented rather than an administrative culture [19]. With reference to this, the importance of NPOs in the South African development sector is undisputed.

The research focussed on this group firstly because, there exists a constant need for NPOs to renovate and reinvent themselves in order to be fully capable to address the various social problems that South Africa faces [8]. One way of re-novating and re-inventing themselves is through changing the way that they operate and conduct their affairs. The advent and development of ICT has revolutionized the way companies conduct business, [3], and the same principles of successful business acumen can be applied in the NPO sector.

Secondly, though there has been ample study on the application of software in the spheres of the corporates, there remains a gap in the study of the same principle to NPO environments.

\section{RESEARCH METHODOLOGY}

\section{A. Research Design}

A mixed design of causal and predictive research was utilised as the research fit the conditions of empirical association, appropriate time order and possibility of replication required for such designs [20].

The researcher also adopted a positivist paradigm which is aligned to the quantitative approach and allows for objectivity and the rationalisation of concepts in measurable terms. 


\section{B. Research Methodology}

To investigate the application of PMS and its influence on project success, statistical analysis was conducted on real project data collected from project-implementing NPOs in the Western Cape.

A non-experimental quantitative approach was used because it allowed the gathered quantifiable data, to be analysed statistically to produce quantified and objective results [20].

Standardised questionnaires consisting of open-ended and closed questions were used as the data collection instrument.

The following research process was followed [21]:

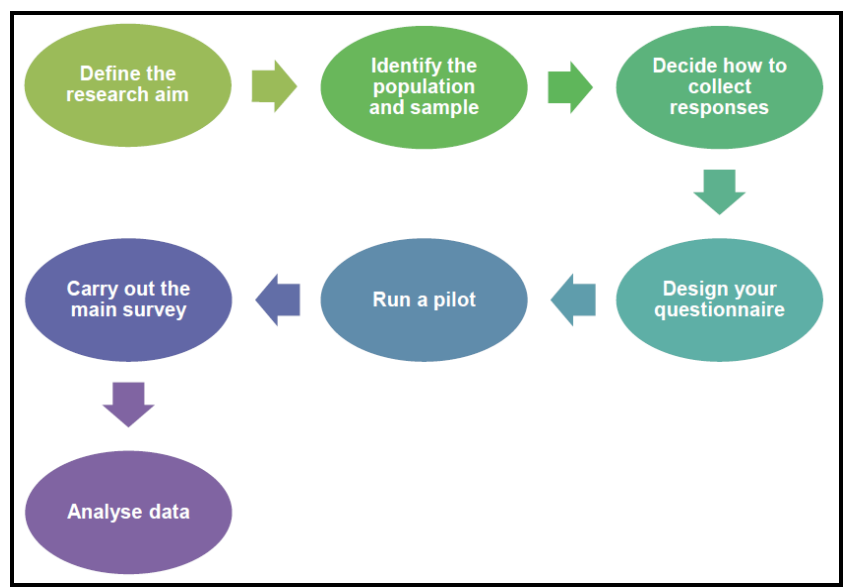

Fig 1: Research Process

The study focussed on NPO's in the Western Cape Province. The Western Cape is one of South Africa's nine provinces and is divided into 5 districts namely: Cape Town, Cape Winelands, Overberg, West Coast, Eden and Central Karoo [22].

In South Africa all NPOs are registered with the Department of Social Development. The researcher utilised the existing database available at the provincial department to identify the NPOs in the Western Cape and furthermore to distinguish between the offerings of the NPO's; that is whether they are services based or project based [18]. The research population was determined to be at least 200 .

Using Sekaran's "Prevalence Sample Size Table", the sample size was determined to be 132 [23].

The fieldwork was conducted during the period of May to August 2018.

\section{FINDINGS}

From the process of data collection, 94 responses were received, which set the response rate at $71.2 \%$. Statistical analysis was thereafter conducted using the SPSS software. The findings are presented below:

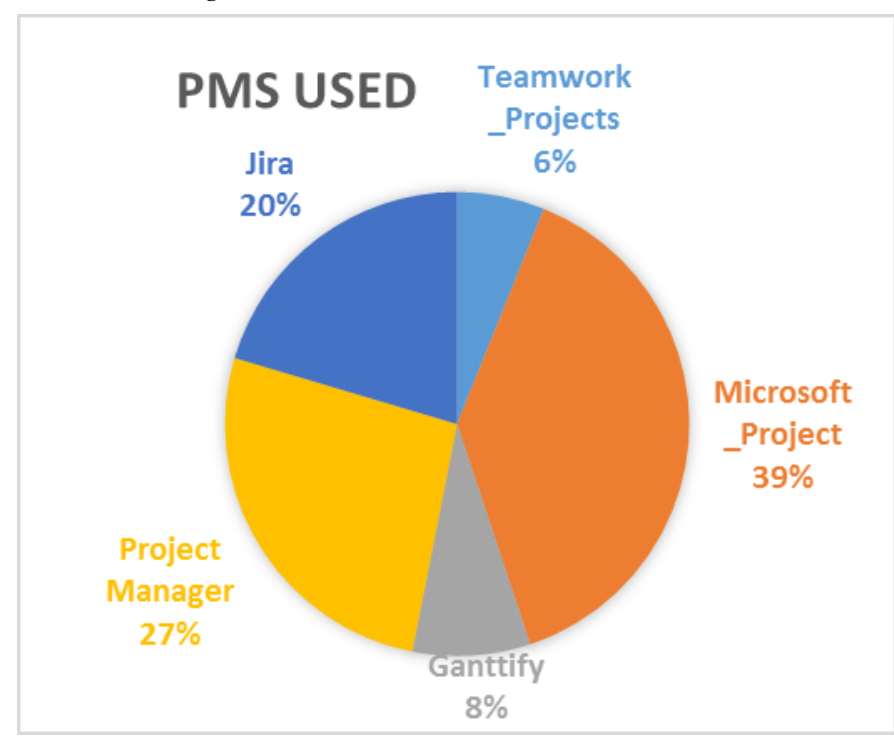

Fig 2: PMS Usage

The most commonly used PMS are Microsoft Project, Project Manager and Jira.

The least used one is Ganttify and it was established that this is due to that people are more familiar with and have used the physical gantt charts longer than the electronic versions.

B. Employee's interactions with PMS relative to project success.

\section{Frequency of PMS use}

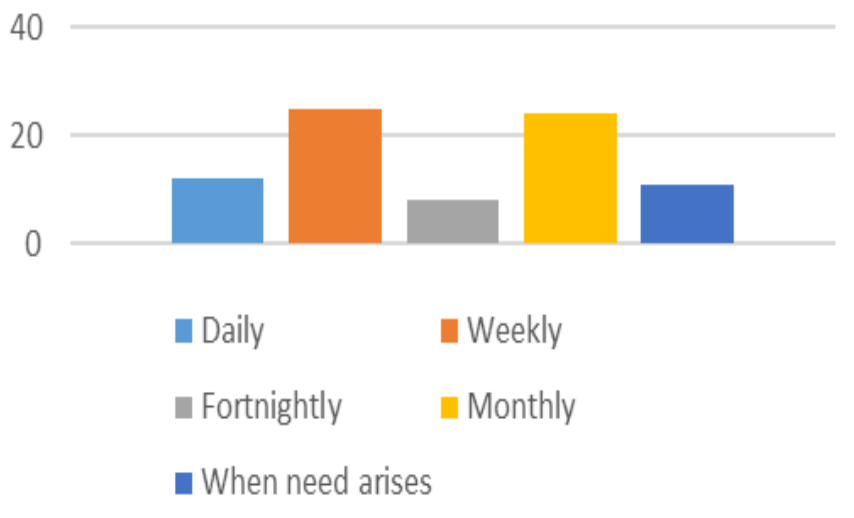

Fig 3: Frequency of PMS use

Most users utilize PMS on a weekly or monthly basis. It should be noted however that though some have used and do have PMS being applied at their organisations, at least $19 \%$ of this population rarely ever use it. 


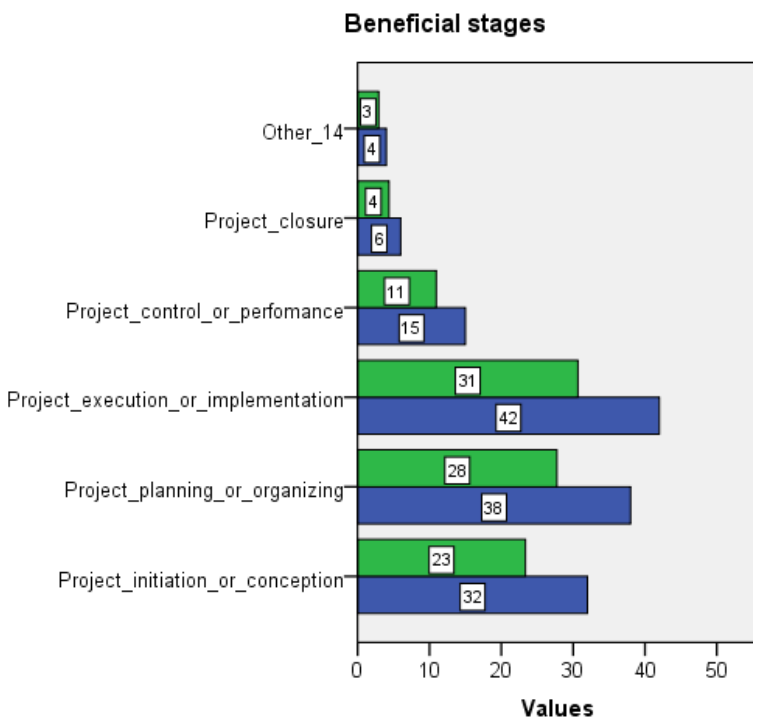

Fig 4: PMS Beneficial Stages

PMS is useful mostly for the project planning/ organizing and the project execution/ implementation project stages.

To note is that at the project closure phase, most of the work would have already been done, hence PMS use and project success are least influenced at this stage.

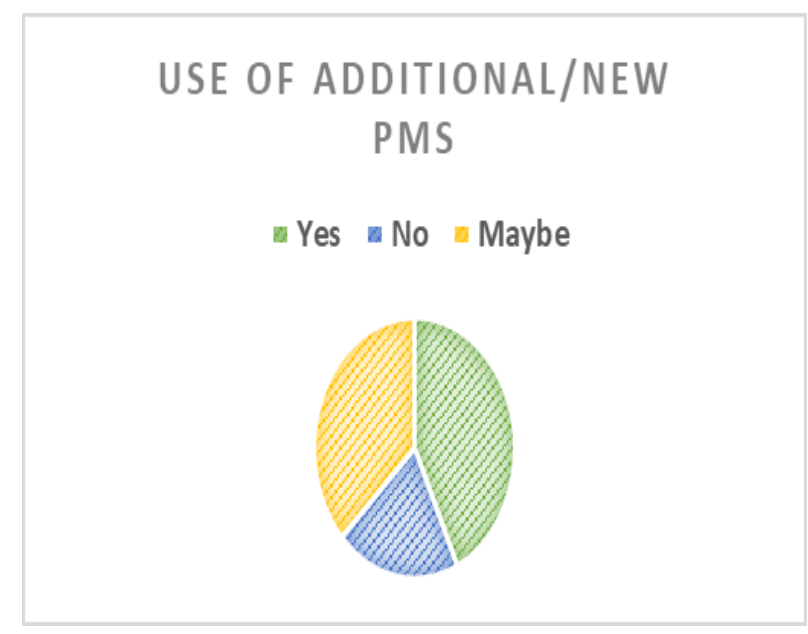

Fig 5: Use of additional/new PMS

A majority of the NPOs would use new or additional PMS as they see a direct relationship between PMS usage and project success.

The main purposes for which they would use it, is to save time, improve their transparency and accountability.

To further assist in influencing success, the following functionalities were described as the ones to be incorporated into the PMS; modifiable to suit organizational needs, simplicity, use of less jargon and better inter-connectedness.

\section{PMS Limitations}

A majority of the users expressed that PMS over-complicates issues and can be time consuming.

The reasons some NPOs will therefore not consider using new/additional PMS is because their scope of work is too small to warrantee usage and PMS may prove to be too complex.

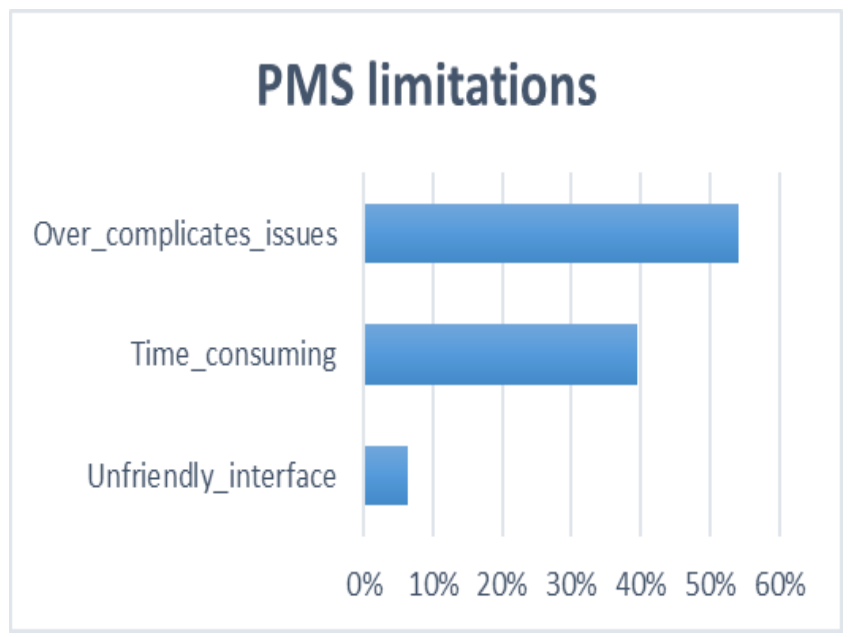

Fig 3: PMS Limitations

\section{RECOMMENDATIONS}

From the study, the researcher would like to propose the following recommendations for adoption by the various parties.

\section{A. Further exploration}

The outcomes of this research are useful to software developers and engineers as it gives real project insight from a specific market of end-users of PMS.

Seeing that some of the software employed locally is designed and managed overseas, this study will assist in giving the developers and engineers a point of reference regarding the local Western Cape context

From the findings of the study, the NPOs voiced a number of functionalities that they would like to see added to the PMS. Examples include discussion boards, modifiability and scalability.

Modification of existing tools - Ganttify is an example of PMS that was formulated from an existing tool, specifically the Gantt Charts. The findings in this study show that the most common tools utilised are the Work Breakdown Structure (WBS) and Critical Path Method (CPM). Useful components of these tools can be modified to make new/ revised software.

\section{B. Practice}

As "project-implementing" NPOs were the case under study, the researcher would like to recommend the following to be incorporated into the NPOs and civil society's practices

Encourage participation in Project Management capacity training for "project-implementing" NPOs. The researcher would like to recommend that NPOs start or continue to engage in trainings to capacitate themselves to be able to fully utilise the various arsenal available to manage projects. This will foster base-level knowledge of project management principles, systems and tools. NPOs would then be able to 
assess and select what is relevant for their respective organisations.

Also this research can serve to inform NPOs about existing technology that they can employ to efficiently tackle their workloads as well as assist in improving the chances of project success.

\section{Further research}

There is scope for fellows in academia, particularly in the Project Management field to further this line of research in terms of:

The current research location was the Western Cape. Future research could include the whole of South Africa. The outcomes of this research could then be used as the nascence baseline study to be compared with findings from outside this province.

Sector/Industry - The current research looked at a case of NPOs. Future research could look at the use of project management software in the private sector or in government.

\section{Strategy}

While still maintaining their independence and autonomy, NPOs' in South Africa are regulated (and sometimes funded) by the South African Government primarily through the Department of Social Development (DSD)

As a regulatory and funding body, the researcher would like to present the following recommendations for incorporating into policy:

Reduce the red-tape and lengthy requirements to enable quicker and easier registration of NPOs.

Upon registration, they will be able to access a host of opportunities and networks in order to boost their work, particularly in aid of projects. Once registered, government will also be better able to keep track of the respective NPOs and their work through the updated databases.

\section{CONCLUSION}

The most commonly used Project Management Software (PMS) are Microsoft Project, Jira and Project Manager. Most users employ PMS on a weekly or monthly basis. Project execution/ implementation and project planning or organizing are viewed as the most crucial stages for which PMS is required.

PMS is not without its limitations which include, the over-complicating of issues and sometimes being time consuming to employ. In light of these limitations, it was revealed that a large percentage of the population would still be keen to try out the PMS at their organisations. The benefits they would be aiming to yield from employing new or additional PMS include to save time, costs and have improved transparency and accountability.

Recommendations were made to software developers and engineers. NPOs, fellow researchers and the Government of South Africa on how to better improve their work, strategies and practices based on the findings of the study.

\section{REFERENCES}

[1] Project Management for Development. (2016). Retrieved from pm4dev.com:

http://www.pm4dev.com/resources/docman/doc_download/5-project-q uality-management.html

[2] Kuratko, D. F., \& Hodgetts, R. M. (2001). Entrepreneurship: Acontemporary Approach. Bloomington: Harcourt College Publishers.

[3] Hall, M., \& O'Dwyer, B. (2017). Accounting, non-governmental organizations and civil society: The importance of nonprofit organizations to understanding accounting, organizations and society. Accounting, Organizations and Society, 63, 1-5. https://doi.org/10.1016/j.aos.2017.11.001

[4] Braude, E. J., \& Bernstein, M. E. (2016). Software engineering: Modern approaches. Long Grove: Waveland press Inc.

[5] Holtzhausen, L. (2013, June). Non-profit organizations bridging the communication divide in a complex South Africa. Public Relations Review, 40(2), 286-293.

https://doi.org/10.1016/j.pubrev.2013.10.006

[6] Ross, E., Romich, R., \& Pena, J. (2016). Working Towards the Future: Technology Use and Evaluation in Workforce Development. Savannah, GA: Association for the Advancement of Computing in Education.

[7] Santos, V. (2015). PMO as a Key Ingredient of Public Sector Projects' Success - Position Paper. Procedia Computer Science, 64, 1190-1199. https://doi.org/10.1016/j.procs.2015.08.546

[8] Steyn, L., 2016. Service delivery protests set for new highs this election year. [Online] Available at: https://mg.co.za/article/2016-05-18-service-delivery-protests-set-for-n ew-highs [Accessed 1211 2017].

[9] Wiggill, M. N., 2014. Donor relationship management practices in the South African non-profit sector. Public Relations Review, pp. 278-285. https://doi.org/10.1016/j.pubrev.2013.10.005

[10] Young, T. L., 2013. Successful project management. London: Kogan Page Limited.

[11] Berman, J., 2007. Maximimizing Project Value: Defining, Managing and measuring for Optimal Return. New York: American Management Association .

[12] Dayani, M., \& Gelbard, R. (2015). Automatic Conversion of Software Specification into a Gantt-chart subject to Organization's Constraints. Procedia Computer Science, 64, 73-78. https://doi.org/10.1016/j.procs.2015.08.465

[13] Cooke-Davies, T., 2002. The "real" success factors on projects. International Journal of Project Management, 3 April, 20(3), pp. 185-190.

[14] Serrador, P. (2013, December). The impact of planning on project success: a literature review. Journal of Modern Project Management, $1(2), 28-39$

[15] Yang, H., 2016. Project Team Right-sizing for the Successful ERP Implementation. Procedia Computer Science, Volume 91, pp. 672-676. https://doi.org/10.1016/j.procs.2016.07.168

[16] Johansson, A., 2017. Huffpost: The 7 Best Project Management Software for Small Businesses. [Online] Available at: https://www.huffingtonpost.com/entry/the-7-best-project-management -software-for-small-businesses_us_5a307c6ee4b0b73d de $46 a 86 f$

[Accessed 2102 2018]. 
[17] Jha, K. N. (2011). Construction project Management: Theory and Practise. Delhi: Pearson India.

[18] Western Cape Government, 2009. What is an NPO?. [Online] Available at: https://www.westerncape.gov.za/other/2009/12/npo_faq_[1].pdf [Accessed 15 September 2017].

[19] Hall, M. \& O'Dwyer, B., 2017. Accounting, non-governmental organizations and civil society: The importance of nonprofit organizations to understanding accounting, organizations and society. Accounting, Organizations and Society, Volume 63, pp. 1-5. https://doi.org/10.1016/j.aos.2017.11.001

[20] Bachman, R. \& Schutt, R. K., 2007. Chapter 5, Causation and Research Designs. In: The Practice of Research in Criminology and Criminal Justice. Thousand Oaks: Pine Forge Press.

[21] Garbarino, S. \& Holland, J., 2009. Quantitative and qualitative methods in impact evaluation and measuring results. Birmingham: GDSRC, University of Birmingham.

Burgess, T. F., 2001. A general introduction to the design of questionnaires for survey research. Leeds: University of Leeds.

[22] Government, W. C., 2017. Health. [Online] Available at: https://www.westerncape.gov.za/dept/health

[23] Sekaran, 2000. Sample Size for a Given Population Size. In: Research methods for business: A skill-building approach. s.l.s.n., p. 295.

\section{BIOGRAPHIES}

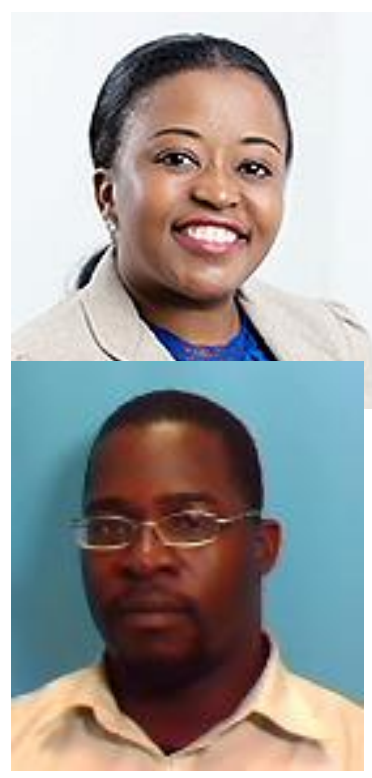

her spare time.

\section{First Author}

Ms Silibaziso Nobukhosi Magwali is a dynamic young lady who holds a National Diploma in Entrepreneurship as well as a Bachelor of Technology in Project Management; both from the Cape Peninsula University of Technology. She is currently pursuing her Masters in Business Administration with a specialization in Project Management at the same institution. She is currently a Project and Operations Officer for The Health Foundation and has previously worked in Business Development for the Department of Health. While she is passionate about health, Ms Magwali also loves issues that have to do with education and offers mentorship and tutorship to high-school and university students in
Engineering at Chinhoyi University of Technology (CUT) in Zimbabwe, from 2004 to 2008. He completed an MSc in Manufacturing Systems and Operations Management (MSOM), from the University of Zimbabwe in as a staff Development fellow from Chinhoyi University of Technology (CUT). His research interests are in environmental management and operations management with a focus on developing countries. To date, he has successfully supervised several MTech Project Management students.

\section{Co-Author}

Stanley Fore is a Lecturer in the Department of Project Management at Cape Peninsula University of Technology (CPUT); department of Project Management. He lectures Project Management to undergraduate students. Prior to joining CPUT, he was lecturing in the Quality and Operations Management department at the University of Johannesburg (UJ) where he taught Operations Management and Quantitative Techniques to undergraduate students. He graduated with a B.Sc.(Honours) from the University of Zimbabwe in and lectured at Gweru Polytechnic from 2002 to 2004. He had previously lectured in the Department of Production 